\title{
Savoir-faire feminino e sua apropriação profissional pelo olhar das relações de gênero
}

\author{
Feminine savoir-faire and its professional appropriation under the optics of gender relationships
}

Maria Fernanda Diogo

Doutora em Psicologia pela Universidade Federal de Santa Catarina (UFSC), pesquisadora do Núcleo de Estudos do Trabalho e Constituição do Sujeito (NETCOS/UFSC), professora do curso de Pedagogia da Faculdade Municipal de Palhoça (FMP),

Palhoça, SC - Brasil, e-mail:

mafediogo@bol.com.br

Recebido: 13/04/2011 Received: $04 / 13 / 2011$

Aprovado: 20/09/2011 Approved: 09/20/2011

\section{Resumo}

A inserção de mulheres no setor produtivo é multifacetada: enquanto algumas se aventuram em profissões consideradas "masculinas", amplo contingente de trabalhadoras ainda procura guetos femininos, como o magistério e a enfermagem. 0 objetivo deste artigo foi realizar uma análise, sob a ótica das relações de gênero, do movimento sócio-histórico inerente a essas duas profissões, desmistificando algumas tramas naturalizantes e biologizantes que enredam as trabalhadoras. $\mathrm{O}$ acesso das mulheres à enfermagem e ao magistério foi historicamente condicionado pela domesticidade das suas relações. Em seus cotidianos, essas profissionais vivenciam "lugares híbridos", cujas atividades produtivas se apoiam no savoir-faire transmitido intergeracionalmente no espaço reprodutivo, incluindo atividades práticas e inter-relacionais. Tais saberes e fazeres não produzem mais-valia e são depreciados econômica e socialmente, pois a lógica capitalista desconsidera que a força de trabalho só se mantém e reproduz a partir do consumo dos valores de uso e das relações interpessoais aí estabelecidas. Desvalorizar uma profissão por ser desenvolvida principalmente por mulheres e assemelhar-se aos saberes tácitos desenvolvidos no âmbito doméstico é uma deturpação que assenta no sexo dos sujeitos a valorização profissional. É preciso realizar um contradiscurso e considerar os setores produtivo e reprodutivo indissociáveis, pois ambos representam diferentes facetas do calidoscópio da experiência humana.

Palavras-chave: Determinações sócio-históricas. Magistério. Enfermagem. Relações de gênero.

\begin{abstract}
Feminine insertion in the productive sector is multifaceted: while some venture in professions regarded as "masculine", wide contingent of workers still seek feminine ghettos, like teaching and the nursing. The objective of this article was to perform an analysis, under the optics of gender relationships, upon the social-historical movement inherent to these two professions, demystifying some naturalizing and biologizing entanglements that involve the workers. Access of women to nursing and to teaching has historically been conditioned to the domesticity of her relationships. In their quotidian these professionals experience "hybrid places", which productive activities lean on the savoir-faire intergenerationaly transmitted in the domestic space, including practical and inter-relational activities. Those knowledge and performaces do not aggregate value and are economically and socially depreciated, because the capitalist logics disregards that workforce is supported and reproduced only through the consumption of the use values and of
\end{abstract}


the interpersonal relations established therein. Depreciating a profession because it is mainly performed by women and assimilated by tacit knowledge developed in the domestic extent is a misrepresentation that bases professional appreciation on the sex of the subjects. It is necessary to carry out a counter-discourse and to consider the productive and reproductive sectors inseparable, since both represent different facets of the kaleidoscope of the human experience.

Keywords: Social-historical determinations. Teaching. Nursing. Gender relationships.

\section{Introdução}

A perspectiva teórica que sustenta o olhar desta pesquisa é a de que as atividades humanas são mediadas pela cultura, ou seja, em se tratando de seres humanos não existem fenômenos naturais. Os sujeitos são constituídos historicamente, sendo, concomitantemente, produtos e produtores de seus contextos, pautados pelas condições materiais, numa relação dialética (Marx \& Engels, 1845/1846/1981). As pessoas fazem história, desenvolvem-na sobre a base herdada pelas gerações anteriores, reproduzindo-a ou modificando-a de acordo com suas necessidades, numa dialética que envolve continuidades, rupturas, processualidades e mútua constituição entre sujeito e sociedade.

Este estudo busca analisar sócio-historicamente algumas profissões femininas clássicas sob a ótica do gênero. As mulheres têm ocupado o mercado de trabalho desde a Revolução Industrial e, em pleno século XXI, ainda observamos assimetrias e hierarquias. Elas geralmente passam despercebidas, como se tudo não passasse de um construto biológico: a mulher ainda é apresentada como tendo uma "natureza" mais dócil, amorosa, paciente, atenciosa, delicada etc. Uma análise das relações de gênero busca transcender o biologicismo, pois "[...] ninguém se faz homem ou mulher apenas pelo fato de ter nascido macho ou fêmea, as identidades subjetivas são masculinizadas e feminizadas a partir de longos processos de inculcação e socialização" (Fonseca, 2000, p. 103).

0 processo de naturalização das diferenças entre homens e mulheres reforça as posições femininas no mercado de trabalho com acentuada segmentação, subalternas e com menores salários (Bruschini, 2007a; Hirata, 2002; Hirata \& Kergoat, 2008; Yannoulas, 2002). 0 capitalismo aparenta oferecer ilimitadas oportunidades profissionais, mas isso se torna uma falácia na medida em que estas são determinadas pela classe, sexo, raça, padrões de comportamento, expectativa de consumo etc. Assim, faz-se necessário destrinchar as complexas tramas intrínsecas às escolhas profissionais, entrecruzando as dimensões sociais, políticas, econômicas, culturais, psicológicas e de gênero.

Bruschini (2007a) aponta para o aumento de mulheres no setor produtivo nacional entre os anos 1990 e 2005 sem, contudo, haver redistribuição social das atividades reprodutivas ${ }^{1}$, permanecendo este um fórum feminino por excelência. Analisando informações da $\mathrm{PNAD}^{2}$, a autora revela que $90 \%$ das mulheres executam afazeres domésticos sem remuneração, somando cerca de 27 horas semanais nesta atividade, contra pouco menos de $45 \%$ dos homens, envolvidos com 10 horas semanais (Bruschini, 2007b).

No mercado de trabalho, as mulheres se concentram na prestação de serviços, educação, saúde, serviços sociais, domésticos e outros trabalhos coletivos enquanto os homens se distribuem mais equitativamente entre as ocupações (Bruschini, 2007b). Verifica-se desigualdade de rendimentos em relação aos homens, desde as ocupações de menor qualificação até aquelas com maior prestígio social (Bruschini, 2007a). Há, ainda, aumento de mulheres em atividades empreendedoras, frequentemente em condições de precariedade (Bulgacov,

1 Reprodução social e cultural diz respeito a atividades domésticas não remuneradas, realizadas geralmente por mulheres, relacionadas à reprodução material e simbólica das pessoas (Yannoulas, 2002). Essas atividades abrigam ampla gama de afazeres, desde lavar, passar, cozinhar, limpar até atividades relativas à administração do lar, gerenciamento doméstico e cuidados com os filhos e demais familiares (Bruschini \& Lombardi, 2007).

2 Pesquisa Nacional por Amostra de Domicílio (PNAD) de 2002, do Instituto Brasileiro de Geografia e Estatística (IBGE). 
2010). Silva (2006) acrescenta que as mulheres são majoritárias no setor informal, seja no emprego doméstico não registrado ou na atividade por conta própria e domiciliar. Para Abramo (2004, p. 225), "los mecanismos de segmentación ocupacional que confinan a la gran mayoría de las mujeres a los segmentos menos valorizados del mercado de trabajo siguen existiendo y reproduciéndose".

Contudo a inserção feminina no mercado de trabalho é multifacetada: também se observa, no cenário produtivo, ampliação das possibilidades de trabalho das mulheres. Hoje elas ocupam postos considerados guetos masculinos até poucos anos atrás e se inserem em vários setores de atividade. Há aumento de executivas, engenheiras, petroleiras, motoristas de ônibus, taxistas, frentistas, vigilantes, entre outras profissões (Cabral, 2006; Diogo \& Coutinho, 2010; Lombardi, 2006; Perreli, 2005). Também aumentaram as mulheres em profissões com elevados índices de formalização, rendimentos e proteção (Bruschini \& Lombardi, 2000).

Partindo do princípio que as relações entre sujeito e sociedade se inscrevem na historicidade, o objetivo deste artigo é contextualizar sócio- historicamente algumas escolhas profissionais tipicamente femininas, o magistério e a enfermagem, desmistificando destinos biologicizados e essencializados (Fonseca, 2000), desnaturalizando as tramas de gênero que as envolvem. No texto, articulam-se dois planos: o primeiro tematiza a inserção da mulher no espaço produtivo e reprodutivo, e o segundo realiza uma análise focalizando essas duas profissões majoritariamente femininas, buscando suas raízes históricas e aproximações teóricas quanto aos seus saberes e fazeres construídos nas relações socialmente estabelecidas.

\section{Relações de gênero e trabalho feminino}

A categoria gênero tem sido amplamente usada em pesquisas acadêmicas e em outros fóruns, tornando imprescindível conceituar o ponto de vista aqui adotado. Relações de gênero são construções sociais de base material, representativas dos processos de produção dos lugares de poder de homens e mulheres em determinada sociedade. A categoria gênero surgiu em substituição a sexo, pois este produzia entendimentos fundamentados somente no biológico. Tornou-se clássica nos estudos de gênero a definição de Scott (1995) com foco nas relações sociais baseadas nas diferenças percebidas entre os sexos e as relações de poder aí engendradas. Esta autora articula gênero com classe social e raça/ etnia, discutindo os jogos de poder perpetrados nestes três eixos.

Gênero é relacional enquanto categoria analítica ou processo social (Saffioti, 1992). As análises de gênero não focam indivíduos, mas buscam dar sentido às transações entre homens e mulheres, entre homens e homens e entre as mulheres. Para Castro (1992, p. 93),

com o conceito de gênero, busca-se a historicidade de estereótiwpos, os símbolos que legitimam assimetrias nas relações entre homens e mulheres, os interesses político-econômicos que atualizam subordinações, as cumplicidades entre vítimas e algozes, e, principalmente, as potencialidades de rebelião.

Várias pesquisadoras apontam que as transações sociais no âmbito produtivo permanecem, de modo geral, hierárquicas e desiguais, ocorrendo a dominância do masculino sobre o feminino. Ao contrário da igualdade de direitos entre homens e mulheres “... antigas defasagens se somam à criação de novos mecanismos de desigualdade, de discriminação e de segmentação ocupacional" (Yannoulas, 2002, p. 26). Assim, utilizar gênero como ferramenta de análise catalisa a compreensão de como as relações de produção tensionam e significam as interações entre os âmbitos produtivo e reprodutivo da vida social (Stecher, Godoy \& Díaz, 2005), proporcionando a reflexão dos “... processos mediante os quais a sociedade utiliza essa diferenciação para hierarquizar as atividades e, portanto, os sexos" (Hirata \& Kergoat, 2008, p. 263).

A discriminação da mulher no mercado de trabalho tem raízes históricas. Este artigo se deterá no caso brasileiro. Rago (1997) aponta que, no fim do século XIX, era significativo o número de mulheres e crianças trabalhando nas fábricas, pois eram força de trabalho barata e abundante, realizando tarefas menos especializadas e mal remuneradas. Com o avanço da industrialização, as mulheres foram gradativamente substituídas pela força de trabalho masculina e direcionadas para os cuidados do lar. Nos anos 1930, a figura da "mãe cívica" redefiniu o lugar feminino na sociedade, sendo sua responsabilidade preparar física, intelectual e moralmente os 
futuros cidadãos da pátria. A ideologia dominante à época considerava que "... o trabalho da mulher fora de casa destruiria a família, tornaria os laços familiares mais frouxos e debilitaria a raça, pois as crianças cresceriam mais soltas, sem a constante vigilância das mães" (Rago, 1997, p. 585). As trabalhadoras eram vistas com preconceito, independente da camada social; nessa época, as únicas formas de profissionalização feminina socialmente aceitas estavam relacionadas aos papéis tradicionais exercidos pelas mulheres (atividades ligadas ao cuidar, educar e servir).

Progressivas mudanças culturais, sociais e econômicas alteraram esse panorama e a mulher foi sendo reabilitada à cena pública, com maior ênfase nas últimas décadas do século XX. A Fundação Carlos Chagas calcula acréscimo em torno de 25 milhões de mulheres no mercado de trabalho entre 1976 e $2002^{3}$. Dados da PNAD/IBGE afirmam que as mulheres chegaram a $52 \%$ da população em idade ativa em $2006^{4}$. Grande parte da inserção laboral feminina se deu de forma segmentada, em postos subalternos, mal-remunerados. Barros, Corseuil, Santos e Firpo (2001, p. 2) apontam que as formas de inserção no mercado geralmente são explicadas em virtude das diferentes características dos trabalhadores, e aqueles com mais educação ou experiência tenderiam aos melhores cargos e salários. "No caso dos diferenciais homem-mulher, contudo, observa-se que: a) há pouca distinção de experiência; b) as mulheres são sensivelmente mais escolarizadas; e c) não obstante, os homens têm obtido melhores condições de trabalho".

Coadunando com esta análise, Nogueira (2004) afirma que as mulheres são alvo de subordinação social, facilitando seu aproveitamento enquanto força de trabalho sub-remunerada. A autora questiona o processo de feminização do setor produtivo: este seria um passo rumo à emancipação da mulher ou uma nova modalidade de precarização ainda maior do trabalho feminino? Ela conclui que as metamorfoses no mundo do trabalho foram positivas no sentido de fazer avançar o difícil processo de emancipação feminina e minimizar as formas de dominação patriarcal no espaço doméstico, mas, por outro lado, elas também agravaram significativamente a precarização das trabalhadoras. É um paradoxo: o modo de produção capitalista criou condições para a emancipação feminina e, por outro, acentuou a sua exploração ao estabelecer uma relação aparentemente "harmônica" entre precarização e trabalho feminino (Nogueira, 2004, p. 4).

O capital utiliza discriminadamente a força de trabalho feminina e masculina, sexualizando as ocupações (Hirata, 2002). Yannoulas (2002, p. 15) denomina o fenômeno da inserção diferencial de homens e mulheres nos mercados de trabalho "segmentação ou segregação dos mercados de trabalho baseada em gênero". Esta pode ser horizontal, relativa à concentração feminina em determinados setores; ou vertical, referente à desvantagem feminina em termos de salários, ascensão profissional e condições de trabalho, independente do ramo de atividade. Faz-se importante contextualizar historicamente a divisão sexual do trabalho, pois tarefas atribuídas a homens e mulheres variam entre culturas e épocas.

Esse fato, historicamente evidenciado, nos confronta com a construção móvel das identidades no trabalho, baseadas nas qualidades de sexo e com o fato de que os atributos de uns e de outros (homens e mulheres) estão submetidos a diferentes modos e polos de atração nesse campo (Lopes \& Leal, 2005, p. 111).

Soares e Oliveira (2004) avaliaram a desigualdade de rendimentos entre homens e mulheres a partir de um recorte por ocupações. As autoras concluíram que essa desigualdade é resultado de características discriminatórias do mercado e da inserção de mulheres de forma concentrada em profissões de baixa qualificação e remuneração. A desigualdade se mantém "... embora as mulheres tenham, sobretudo, maior escolaridade do que os homens, a despeito da urbanização e do desenvolvimento econômico, e apesar da luta feminista por igualdades de direitos na família e no mercado de trabalho travada nas últimas décadas" (Soares \& Oliveira, 2004, p. 24).

Com base nos levantamentos acerca da inserção feminina no mercado de trabalho, surgiu a indagação que motivou esta pesquisa: qual o percurso histórico e as características comuns aos saberes e fazeres das profissões ocupadas maciçamente por mulheres?

\footnotetext{
3 Dados disponíveis no site da Fundação Carlos Chagas. Recuperado em 12 dez. 2009, em http://www.fcc.org.br/mulher/ series_historicas/mmt.html

4 Dados disponíveis no site do IBGE. Recuperado em 20 dez. 2009, em http://www. www.ibge.gov.br
} 


\section{0 caminho percorrido}

Esta pesquisa se caracteriza por ser um estudo bibliográfico. A pesquisa bibliográfica compreende a identificação em base de dados, seleção, compilação, fichamento dos tópicos de interesse da pesquisa. Inicialmente, foi realizado um levantamento em base de dados ${ }^{5}$ sobre artigos acadêmicos com foco nas escolhas profissionais "tipicamente femininas". Numa segunda etapa, foram selecionados artigos que convergiam suas análises para o magistério (principalmente séries iniciais) e para a enfermagem. A escolha destas deu-se pela evidência de uma maior quantidade de artigos sobre tais profissões que realizavam análises de gênero. Os sentidos atribuídos à escolha ou exercício maciçamente feminino nas áreas do magistério e enfermagem foram investigados a partir de um segundo levantamento ${ }^{6}$. Foram realizadas leituras detalhadas de cada artigo escolhido buscando levantar as principais características atribuídas ao exercício profissional nestas áreas desde a perspectiva teórica inicialmente traçada.

\section{Segmentos femininos no mercado de trabalho e a questão do cuidar}

Segundo o IBGE, mulheres integrantes da População Economicamente Ativa situam-se 22\% na administração pública, educação, defesa, segurança e saúde; $17,4 \%$ no comércio; $16,5 \%$ na área de serviços domésticos; $13,3 \%$ em serviços prestados às empresas; $13,1 \%$ no setor industrial; $0,6 \%$ na construção civil; e 17,0\% em outros serviços/atividades ${ }^{7}$. Bruschini (2007a) aponta como profissões de maciça concentração feminina professoras de séries iniciais, psicólogas, secretárias, recepcionistas, enfermeiras, técnicas de enfermagem, cabeleireiras, esteticistas, faxineiras, arrumadeiras e cozinheiras.

A análise da concentração feminina em alguns setores tem vários ângulos. Perosa (2008, p. 54) aponta o processo educacional como decisivo para compreender como a desigualdade entre os sexos pode persistir, reproduzir-se ou se alterar, pois esta inculca "disposições femininas diferenciadas" seja no seio familiar ou na socialização escolar, predispondo mulheres ao exercício de determinadas profissões pela "educação para a submissão" (Perosa (2008, p. 54). Kergoat (1986 apud Castro, 1992) também considera a socialização feminina no âmbito da família cercada por estereótipos de gênero que as impele para determinadas ocupações e processos de trabalhos. "As desigualdades por gênero passam pela ordenação da reprodução, uma das instâncias em que os antagonismos entre sexos mais se evidenciam" (Castro, 1992, p. 86).

Há uma tendência em separar dicotomicamente os setores produtivo e reprodutivo, principalmente em função das relações de gênero aí perpetradas, associando o universo feminino ao trabalho doméstico (Hirata \& Kergoat, 2008). Diogo e Maheirie (2008) apontam para a perpetuação geracional do trabalho doméstico em mãos femininas por meio da iniciação das filhas nessas tarefas na condição de aprendizes. Fonseca enfatiza a dissimetria instaurada entre homens e mulheres no terreno das trocas simbólicas ocorridas nas famílias e como isso repercute na forma como o mercado se apropria da força de trabalho feminina, pois, para essa autora, "as mulheres, encarregadas da gestão do capital simbólico das famílias são muito logicamente instadas a carregar este papel para o interior das empresas" (Fonseca, 2000, p. 97).

As atividades realizadas no seio familiar ultrapassam o enfoque centrado na realização de tarefas mecânicas e rotineiras. Araújo e Scalon (2005) descrevem o cuidado - atenção social, física, psíquica e emocional - como constitutivo da vida social familiar e um aspecto extremamente importante das relações aí estabelecidas. Importante salientar que as práticas de cuidado não se restringem ao âmbito privado, pois essas atividades deixam suas marcas nas instituições sociais, produzindo uma relação de interdependência entre as esferas (Sorj, 2010).

Atividades de cuidado dizem respeito às práticas cotidianas, "aquilo que se aglutina sob a forma de ações ou intervenções, que colaboram para gerar, organizar ou (re)estabelecer esperança, autonomia,

5 Base de dados pesquisada: http://www.bvs-psi.org.br/. Descritores da primeira parte da pesquisa: escolhas profissionais femininas, trabalhos tipicamente femininos, trabalhos de mulheres, feminização no trabalho.

6 Base de dados pesquisada: http://www.bvs-psi.org.br/. Descritores da segunda parte da pesquisa: enfermagem e gênero; saúde e gênero; magistério e gênero; educação e gênero.

7 Dados disponíveis no site do IBGE. Recuperado em 12 dez. 2009, em http://www.ibge.gov.br 
a liberdade de escolha, as relações humanas e o sentido da vida" (Martines \& Machado, 2010, p. 329). Para Soares (2010), o ato de cuidar carrega a "invisibilidade" típica dos trabalhos domésticos e, também, um padrão de qualidade e reconhecimento baseado no âmbito privado: o bom trabalho de cuidar é aquele que é feito como se fosse para um membro da sua própria família. A partir do ato de cuidar, estabelecem-se laços afetivos e encontros intersubjetivos, ou seja, a noção de cuidado desloca a relação sujeito-objeto para sujeito-sujeito.

Sorj (2010) pontua que as atividades de cuidado têm suas raízes na esfera privada e foram, por muito tempo, concebidas como naturalmente femininas, tratadas, portanto, como "obrigação das mulheres". Tal fato as manteve em posições subordinadas no ambiente familiar, frequentemente conciliando mais de uma jornada de trabalho. A autora debate a necessidade de fomentar uma discussão na sociedade acerca desse tema e pensar políticas públicas que busquem alterar as relações de poder dentro da família.

0 ato de cuidar é comumente observado no cotidiano das profissões tipicamente femininas, podendo-se concluir que as atividades realizadas no espaço privado influenciam a participação feminina no espaço público. As empresas se apropriam do "treinamento informal" recebido pelas mulheres desde crianças, naturalizando o desenvolvimento dessas habilidades e as desqualificando material e simbolicamente (Fonseca, 2000) em profissões de baixa qualificação e remuneração (Bruschini, 2007a; Hirata, 2002; Soares \& Oliveira, 2004). A porta de acesso das mulheres à esfera pública não por acaso se deu, prioritariamente, por meio de profissões como a enfermagem e o magistério (Moreira, 1999), ocupações com funções muito assemelhadas àquelas desempenhadas no núcleo familiar.

\section{Magistério e enfermagem: Enlaces da mesma trama}

Foram selecionados para este estudo alguns artigos que abordavam o magistério e a enfermagem desde a perspectiva da análise das relações de gênero, buscando, neste recorte, transcender o aspecto meramente descritivo e revelar nuances sociais, políticas, econômicas e culturais que residiram nestas opções profissionais. Iniciou-se a exposição pelo magistério.
Estudos sobre o trabalho no magistério são numerosos, porém balanço da historiografia da educação realizado por Chamon (2006) destaca a análise sob a perspectiva de gênero como recente e ainda pouco explorada no Brasil e em outros países. A feminização da profissão esteve associada à sua desvalorização econômica e social: inicialmente o magistério foi uma profissão realizada por homens, contudo a intensificação da industrialização, urbanização e migração tornou necessário democratizar a educação pública. Em decorrência da desvalorização, do atraso salarial e do desprestígio, os homens abandonaram a profissão (Urbano, 2009). Gradativamente, o discurso convencional se reorganizou e qualidades como abnegação, altruísmo, dedicação e vocação passaram a ser exaltadas no magistério, num discurso maciçamente dirigido às mulheres.

Para Chamon (2006), o ideal da "vocação" feminina para o magistério foi construído com funções políticas. As mulheres já serviam a pátria como "mães cívicas" e passaram a ser instadas a servi-la também como professoras, cuidando e instruindo crianças com os valores sociais e morais vigentes em "uma educação cívica que buscava construir mentes e corações disciplinados em corpos saudáveis, para assim forjar a nacionalidade brasileira" (Carvalho, 1998, p. 3).

Souza, Catani, Souza e Bueno (1996) apontam que, na virada do século XX, as mulheres representavam a maioria dos alunos das escolas normais de preparação para o magistério. Dominava a associação do magistério a características "tipicamente femininas". Como as opções profissionais apresentadas às mulheres eram muito limitadas (Santos, 2008), ser professora se tornou uma boa oportunidade para a entrada feminina no espaço público, contando com elevado nível de aprovação social.

O magistério primário foi a única profissão, no período da primeira República, possível às mulheres brancas e de classe média. A educação feminina era diferente da masculina e as mulheres eram preparadas para o lar, para boa esposa e mãe, e tendo essas qualificações, as senhoras estariam preparadas para atuação docente (Urbano, 2009).

Assim, a ampla feminização do magistério esteve vinculada à assimilação da profissão a "características femininas", naturalizando esta escolha (Rabelo, 2007). Articular as dimensões produtiva e 
reprodutiva propiciou o acesso feminino ao mercado de trabalho, porém, por outro lado, as docentes passaram a ser vistas como "mães substitutas" ou "tias", tendo seu reconhecimento profissional sensivelmente diminuído. A imagem socialmente difundida era que as professoras eram profissionais pouco eruditas e intelectualizadas, que se relacionavam mal com o conhecimento e a racionalidade, sendo mais emotivas e maternais (Carvalho, 1998).

As mulheres, detentoras de um savoir-faire no âmbito doméstico, com habilidades na organização e higienização de seus lares, na ordenação dos espaços e dos tempos, na disciplinarização das crianças, e ainda mais "econômicas", seriam as profissionais ideais para contribuir na construção da nova cultura escolar e consolidação de uma nova ordem urbana pela "boa formação de seus cidadãos” (Chamon, 2006, p. 12).

Carvalho (1996, p. 79) ressalta a semelhança do trabalho doméstico ao escolar enquanto referência para as próprias educadoras. "Pesquisas em diversos países têm demonstrado que a construção histórica de sua imagem social e de sua prática teve origem na vinculação entre educação escolar e família, entre mãe e professora". Para a autora, no magistério há especial relevância no conceito de qualificação tácita ${ }^{8}$, social ou informal, indo além dos conhecimentos e técnicas. Pesquisa etnográfica citada pela autora com professores/as de ensino fundamental aponta que estes/as definiram profissionalismo a partir do ângulo pessoal, não desconsiderando as dimensões intelectuais, mas priorizando o conceito de cuidado como trabalho pedagógico. A despeito das práticas de cuidado e demais qualificações tácitas oriundas do meio familiar serem fundamentais, segundo Carvalho (1996), essas não conferem legitimidade profissional e passam ao largo das pesquisas acadêmicas, pois essa noção não possui estatuto teórico e dificilmente se constitui em objeto de estudo.

Silva (2006) reforça que o exercício da docência está ideologicamente identificado aos processos reprodutivos, pois as professoras ainda são identificadas como educadoras "natas", levando a profissão para espaços marginais às relações sociais e econômicas. Segundo o autor, a identificação entre docência e vocação corrobora com a desprofissionalização da profissão, descaracteriza os saberes construídos na formação e experiência profissional e reforça a divisão sexual (e hierarquizada) do trabalho.

A correspondência do trabalho nas instituições educativas com o trabalho doméstico e a contaminação das práticas educativas pelos processos materno-afetivos disseminam uma ideologia que desqualifica o trabalho e as funções dessas instituições, visto que cuidar de crianças [...] é tarefa da família e dos pais e mães, o que, para a sociedade, não se configura como trabalho (Silva, 2006, p. 334).

Para Marx (1867/1998), todo trabalho produz valores de uso e/ou valores de troca. 0 trabalho na sua dimensão concreta gera valores de uso, ou seja, satisfaz as necessidades humanas e é condição universal do metabolismo entre as pessoas e a natureza. Já o trabalho abstrato é produtor de valores de troca, de mais-valia, excedente quantitativo do tempo de trabalho socialmente empregado na produção. A sociedade capitalista se objetiva e mantém pela produção de valores de troca. 0 trabalho doméstico não produz mercadorias, não gera mais-valia, não é considerado atividade econômica, ou seja, não se configura como trabalho pela ótica capitalista (Marx, 1867/1998). Para citar como essa concepção está presente na nossa sociedade, Bruschini (2007b) aponta que a maioria das pesquisas oficiais ainda apresenta uma metodologia que prioriza a análise das relações de produção capitalistas em detrimento dos setores marginalmente integrados, como é o caso dos serviços domésticos, mantendo a classificação de "inatividade econômica".

0 magistério se assemelha em vários aspectos ao trabalho reprodutivo e é um campo majoritariamente feminino: a literatura aponta que aqui se assentam as principais justificativas para os baixos salários, condições inadequadas de trabalho, preconceito em relação à capacidade intelectual das professoras e pouco prestígio social da profissão. As mulheres representam $78,2 \%$ do total de professores brasileiros, correspondendo a 3,7\% da população ocupada no Brasil (Souza, 2008). Estão concentradas na educação infantil e séries iniciais do ensino fundamental, etapas pouco valorizadas na carreira do magistério; já na segunda fase do ensino

8 Conhecimento tácito é uma "síntese de conhecimentos esparsos e práticas laborais vividas ao longo de trajetórias que se diferenciam a partir das diferentes oportunidades e subjetividades dos trabalhadores” (Kuenzer, 2002, p. 2). Essa característica não propicia sua sistematização teórica, pois seu desenvolvimento depende das relações sociais vividas.

Psicol. Argum. 2012 out./dez., 30(71), 731-743 
fundamental e médio, etapas historicamente mais valorizadas e associadas com uma maior qualificação dos professores, aumenta o número de homens (Codo et al., 1999 citado por Silva, 2006). Também são restritas mulheres trabalhando em cursos profissionalizantes nas escolas técnicas (Souza, 2008).

Na opinião de Silva (2006), a grande feminização do trabalho docente, principalmente no nível básico, é o elo fundamental na disseminação de uma ideologia que desmantela a organização coletiva dos/as trabalhadores/as da educação, pois, na medida em que esse tipo de trabalho se vincula à reprodução e à vocação, “... não requer valorização nem tampouco organização política de suas trabalhadoras" (Silva, 2006, p. 330). A ideologia da "vocação" feminina para o magistério faz os atributos tácitos desenvolvidos no seio familiar serem ignorados pela lógica do mercado: não merecem reconhecimento social nem remuneração diferenciada, sendo desconsiderados todos os anos empregados nesse aprendizado. Além disso, não são adquiridas em um fórum institucional reconhecido, facilitando sua naturalização e negação.

Várias semelhanças podem ser pontuadas entre magistério e enfermagem: ambos são exercidos maciçamente por mulheres, lidam diretamente com práticas de cuidados, têm baixa remuneração e reconhecimento. No imaginário social referente à enfermagem, também há estreita vinculação com a "natureza feminina" e a "devoção", produzida e reproduzida nos múltiplos cotidianos das relações de gênero, sejam domésticas, educacionais ou profissionais.

A enfermagem surgiu como um serviço organizado pelas instituições sacras. Assim, seu exercício institucional deu-se inicialmente, e por um longo período, como majoritariamente feminino transmitido de mulher para mulher - e caritativo (Lopes \& Leal, 2005). Para Moreira (1999, p. 59), o ato de cuidar remetia a uma prática "moralmente idônea" e exigia devoção, desprendimento, submissão e capacidade de gestão do espaço hospitalar tal qual uma casa.

Quando passou à prática leiga, a enfermagem se converteu em importante vetor de emancipação econômica e social de mulheres brasileiras de classe média. Detalhe relevante apontado por Padilha, Vaghetti e Brodersen (2006) é que nos primórdios da profissão a maioria das escolas de ensino superior só aceitava alunas. Esta foi a primeira profissão feminina universitária que auxiliou na sustentação aos programas de saúde pública e funcionamento dos serviços de saúde (Aperibense \& Barreira, 2008).
Santos e Luchesi (2002) apontam a subordinação do trabalho da enfermagem à prática médica desde o surgimento da profissão: era necessário alguém que cuidasse do paciente, do ambiente e executasse as ordens médicas. Assim, o saber da enfermagem constituiu-se numa prática amplamente ligada ao trabalho manual feminino, ao cuidado, cercado pelas virtudes da modéstia, obediência e abnegação. Para Amorim (2009, p. 65), a enfermagem sempre esteve relacionada com devoção e submissão, pois "o cuidar diz respeito a homens e mulheres, porém a divisão do trabalho levou a uma construção social das mulheres na qual tarefas que envolvem sensibilidade, carinho, afetuosidade são consideradas femininas".

Padilha, Vaghetti e Brodersen (2006) ressaltam a estreita vinculação entre o feminino e o exercício da enfermagem a partir da análise de textos legais brasileiros (documentos, decretos e leis reguladoras da profissão). Um detalhe trazido pelos autores que denuncia a feminização da profissão desde seu início: os documentos produzidos até a década de 1960 referiam-se "às enfermeiras" sempre no feminino. 0 uso do termo "enfermeiro" fazia referência aos cursos práticos da época: enfermeiros do exército ou polícia militar, entendendo-se com isso que estes cursos eram destinados somente a pessoas do sexo masculino.

Até os dias atuais, persiste a feminização da enfermagem brasileira, tanto no nível universitário como no técnico (Lopes \& Leal, 2005), contudo, em conformidade com os estudos acerca do magistério, restritos são aqueles que problematizam essa questão na perspectiva do gênero. Para Moreira (1999), leituras maniqueístas acerca das posições de gênero no trabalho de enfermagem visam a encobrir "... a complexidade que permeia as relações sociais e as produções dos sujeitos no cotidiano das práticas sociais" (Moreira, 1999, p. 56). Para Moreira, as mulheres historicamente são detentoras dos saberes de saúde e cuidado, transmitidos geracionalmente. Assim, vocação e competência técnica se uniram na formação da identidade profissional dessa categoria maciçamente feminina.

Para Lopes e Leal (2005), práticas médicas (tratamento) e de enfermagem (cuidado) traduzem as ligações entre natureza e legitimidade e, também, entre gênero, classe e poder. Há uma hierarquia social do conteúdo das primeiras como masculinas, científicas e portadoras de valores da "verdadeira" qualificação profissional e das segundas como femininas, 
empíricas, rotineiras, taylorizadas, de presença constante e intensiva e, também, de hotelaria. "A medicina, enquanto prática terapêutica, não tem sexo; a enfermagem, enquanto prática do cuidado, tem apenas um sexo no imaginário social - o feminino" (Lopes \& Leal, 2005, p. 119). Amorim (2009) também aponta que, para a sociedade, o lugar de cuidador não é masculino. A dicotomia entre cuidado e tratamento define uma série de conflitos e relações de poder que se estabelecem nas práticas profissionais dentro da própria enfermagem e na sua relação com a medicina (Bandeira \& Oliveira, 1998).

0 valor atribuído ao feminino na enfermagem é tão forte que o contingente masculino de enfermeiros chegou a sofrer com os olhares indagadores acerca de sua condição erótica (Moreira, 1999). Além disso, a profissão está identificada a certos símbolos e situações que a desvalorizam perante a imagem masculina socialmente cobiçada. Estudos populacionais sobre qualificação e emprego citados por Lopes e Leal (2005) apontam como uma tendência desse ramo ser atrativo para rapazes das camadas mais pobres, particularmente na categoria de técnicos, na expectativa de conseguir rápida inserção no mercado devido ao incremento de oportunidades.

Na enfermagem, há uma segregação ocupacional nos postos de trabalho - tal qual observado no magistério, no qual as mulheres são predominantes nas séries iniciais. Segundo Lopes e Leal (2005), as mulheres são contratadas pelos seus atributos "naturais" tais como dedicação e paciência; os homens o são pela sua força física e pela noção de risco técnico, concentrados nas áreas de Psiquiatria, Ortopedia, Serviços Radiológicos etc. Amorim (2009) ainda aponta maior presença masculina no gerenciamento das atividades e naquelas que envolvem alta tecnologia hospitalar.

Estudando a inserção masculina na área de enfermagem, Wainberg (2004) assinala que os auxiliares de enfermagem evitavam atividades relacionadas ao cuidado com os pacientes na busca de fugir do estigma desvalorizante da profissão. Os homens se concentravam em atividades que necessitavam de força física e, também, no trabalho noturno, reforçando expectativas sobre estereótipos sexuais; as mulheres atuavam diretamente no cuidado aos enfermos.

Pelas reflexões anteriores observamos que a noção de cuidar de um ser humano trama os trabalhos nas áreas de magistério e enfermagem. Formal e tecnicamente diferentes, ambas as profissões detêm similaridades com as atividades reprodutivas, são basicamente exercidas por mulheres, socialmente desvalorizadas e mal remuneradas. Reproduz-se a segregação horizontal de gênero no magistério e na enfermagem e, também, a vertical, pois, dentro das profissões, encontramos diferenças de sexo na ocupação dos postos de trabalho (Yannoulas, 2002). Como os atributos tácitos característicos dessas profissões são considerados "natos" às mulheres, tais atributos são sumariamente ignorados pelo capitalismo, afinal algo tão "natural" não precisa de remuneração diferenciada ou reconhecimento social.

\section{Tecendo costuras acerca dos trabalhos produtivos tipicamente femininos e os reprodutivos}

A tendência em separar dicotomicamente os setores produtivo e reprodutivo repercute nas relações de gênero, pois as mulheres são as principais responsáveis pelas atividades domésticas. A qualidade das relações estabelecidas no âmbito privado é claramente diferente daquela necessária à produção de mais-valia, contudo a lógica do sistema capitalista desconsidera que a força de trabalho só se mantém e reproduz a partir do consumo de valores de uso produzidos pelo trabalho doméstico. Além disso, na esfera reprodutiva não se executam somente atividades mecânicas e rotineiras: toma especial relevância a gestão do capital simbólico (Fonseca, 2000) por meio das práticas cotidianas de cuidado: ações e intervenções sociais, físicas, psíquicas e emocionais dirigidas ao microcosmo familiar (Araújo \& Scalon, 2005; Martines \& Machado, 2010; Soares, 2010).

Apesar de o trabalho doméstico não contar na formação do Produto Interno Bruto dos países, análise de informações da PNAD/IBGE no período de 2001 a 2005 permitiu a Melo, Considera e Di Sabbato (2007) concluir que corresponderia aproximadamente a $11,2 \%$ do PIB brasileiro no período citado. Ainda segundo os autores, o fato de o trabalho doméstico - e dos conhecimentos tácitos aí gerados - não ter reconhecimento origina-se em uma discriminação histórica, reforçando sua invisibilidade característica e a inferioridade da mulher na sociedade. Como apontam Abramo e Todaro (2008, p. 152), os custos da reprodução e as atividades de cuidado "... são tomados como um dado na 
economia convencional, e considerados 'bens gratuitos fornecidos pela natureza'".

Boa parte dos trabalhos de ensino, assistenciais e assemelhados reproduz algumas características domésticas. Saberes tácitos, técnicos e relacionais se mesclam nos cotidianos. Esses fóruns se tornaram guetos ocupacionais femininos, pois o acesso de alguns grupos de mulheres ao trabalho pago foi historicamente condicionado pela domesticidade das suas relações. Há, pois, uma interpenetração nas esferas produtiva e reprodutiva na definição da situação de grande contingente de mulheres: são "lugares híbridos", cujas atividades produtivas se apoiam no savoir-faire transmitido intergeracionalmente.

Trabalhar não é somente executar uma atividade técnica, também implica no engajamento do corpo do/a trabalhador/a, nos gestos, na sua mobilização subjetiva, na capacidade de refletir, interpretar e reagir às situações. Faz-se necessário lutar por uma maior valorização dos saberes e fazeres realizados na esfera reprodutiva como integrantes dos saberes e fazeres que movem a sociedade, independente destes serem realizados por homens ou mulheres, valorizando a "... construção subjetiva das emoções, do afeto e da solidariedade como parte constitutiva do desenvolvimento das interações humanas" (Araújo \& Scalon, 2005, p. 22).

Só desta forma seria possível fomentar a redistribuição de tais atividades, até então concentradas em mãos femininas. Concordando com Sorj (2010), é necessário que a sociedade (re)discuta a divisão sexual dos trabalhos domésticos e fomente políticas públicas visando a alteração das relações de poder dentro da família. É preciso passar a considerar a indissociabilidade dos setores produtivo e reprodutivo, pois ambos representam diferentes facetas do calidoscópio da experiência humana, independente do sexo de quem o executa. "A recusa da falsa dicotomia entre produção e reprodução significa a negação das formas burguesas de relações, que são determinantes tanto na esfera doméstica quanto nos diversos locais de trabalho" (Silva, 2006, p. 336).

A partir deste reconhecimento e da desmistificação da "vocação" feminina para determinados papéis sociais, seria possível operar a valorização de algumas profissões ocupadas maciçamente por mulheres, como o magistério e a enfermagem. Desvalorizar uma profissão porque é desenvolvida principalmente por mulheres e se assemelha aos saberes tácitos conquistados no âmbito doméstico é uma deturpação que coloca no sexo dos sujeitos a valoração profissional, contribui para o seu desprestígio social e não fomenta a cidadania.

As sociedades são e sempre serão construídas por sujeitos diferentes em termos de raça, gênero, credos, percepções etc. É necessário olhá-las pela epistemologia feminista (Rago, 1998) e realizar um contradiscurso, não no sentido de buscar instituir um outro sujeito universal, mas ponderar as mulheres enquanto sujeitos construídos no jogo das relações sociais. Pesquisas que estudam o trabalho feminino devem buscar a articulação dos sentidos emergentes nas relações de gênero, pois explicam os atributos valorados por cada cultura, e questionar o modo dominante da produção de conhecimento científico, desuniversalizando o conceito de "... homem-branco-heterossexual-civilizado-do-Primeiro-Mundo, deixando de lado todos aqueles que escapam deste modelo de referência" (Rago, 1998, p. 25).

Por fim, cabe lembrar os Objetivos de Desenvolvimento do Milênio descritos pelo Fundo de Desenvolvimento das Nações Unidas para a Mulher (Unifem). São prioridades a redução da pobreza, o alcance do desenvolvimento sustentável, o combate ao HIV/Aids, o incremento de uma parceria global para o desenvolvimento e a promoção da igualdade de gênero. Especificamente em relação ao último tópico, preconiza-se que homens e mulheres sejam parceiros e estabeleçam relações em termos de igualdade. Devemos buscar a modificação da base cultural herdada de nossos antepassados e fazer um futuro diferente do presente, transformando-o em algo mais justo para todos/as, pois, enquanto se evidenciar o jogo de forças descrito por Nogueira (2004) - da feminização do trabalho implicar em precarização social e maior grau de exploração -, viveremos uma sociedade não democrática.

\section{Referências}

Abramo, L., \& Todaro, R. (2008). Custos do trabalho de homens e mulheres na América Latina. In A. de Oliveira et al. (Org.). Mercado de trabalho e gênero: comparações internacionais (pp. 141-158). Rio de Janeiro: FGV.

Abramo, L. (2004). ¿Inserción laboral de las mujeres en América Latina: Una fuerza de trabajo secundaria? Revista de Estudos Feministas, 12(2), 224-235. 
Amorim, R. da C. (2009). A questão do gênero no ensinar enfermagem. Revista de Enfermagem da UERJ, 17(1), 64-68. Recuperado em 16 out. 2009, em http://www.facenf.uerj.br/v17n1/v17n1a12.pdf

Aperibense, P. G. G. de S., \& Barreira, I. de A. (2008). Nexos entre Enfermagem, Nutrição e Serviço Social, profissões femininas pioneiras na área de saúde. Revista da Escola de Enfermagem da USP, 42(3), 474-482. Recuperado em 15 out. 2009, em http://www.scielo.br/scielo.php?script= sci_arttext\&pid=S0080-62342008000300009\& $\operatorname{lng}=\mathrm{en} \& \mathrm{nrm}=\mathrm{iso}$

Araújo, C., \& Scalon, C. (2005). Percepções e atitudes de mulheres e homens sobre a conciliação de família e trabalho pago no Brasil. In C. Araújo \& C. Scalon (Org.). Gênero, família e trabalho no Brasil (pp. 15-77). Rio de Janeiro: FGV.

Bandeira, L., \& Oliveira, E. M. de. (1998). Representações de gênero e moralidade na prática profissional da enfermagem. Revista Brasileira de Enfermagem, 51(4), 677-696. Recuperado em 26 out. 2009, em http://bases.bireme.br/cgi-bin/wxislind.exe/iah/ online/?IsisScript=iah/iah.xis\&src=google \&base=LI LACS\&lang=p\&nextAction=lnk\&exprSearch $=283383$ \&indexSearch=ID

Barros, R. P. de, Corseuil, C. H., Santos, D. D. dos, \& Firpo, S. P. (2001). Inserção no mercado de trabalho: Diferenças por sexo e consequências sobre o bem-estar. Texto para discussão n. 796. Instituto de Pesquisa Econômica Aplicada (IPEA). Rio de Janeiro. Recuperado em 20 out. 2009, em http://www.ipea.gov.br

Bruschini, M. C. A. (2007a). Trabalho e gênero no Brasil nos últimos dez anos. Cadernos de Pesquisa, 37(132), 537-572. Recuperado em 16 out. 2009, em http://www.scielo.br/scielo.php?pid=S0100$-15742007000300003 \&$ script=sci_arttext\&tlng=en

Bruschini, M. C. A. (2007b). Trabalho doméstico: Inatividade econômica ou trabalho não remunerado? Anais do Seminário Internacional Mercado de Trabalho e Gênero. São Paulo: Universidade de São Paulo; Rio de Janeiro: Universidade Federal do Rio de Janeiro.

Bruschini, C. \& Lombardi, M. R. (2000). A bipolaridade do trabalho feminino no Brasil contemporâneo. Cadernos de Pesquisa, 110, 67-104. Recuperado em 12 fev. 2009, em http://www.scielo.br/pdf/\%0D/cp/ n110/n110a03.pdf.
Bulgacov, Y. L. M. et al. (2010). Atividade empreendedora da mulher brasileira: Trabalho precário ou trabalho decente? Psicologia Argumento, 28(63), 337-349. Recuperado em 2 nov. 2011, em http://www2.pucpr. br/reol/index.php/PA?dd1=3935\&dd99=view

Cabral, C. G. (2006). 0 conhecimento dialogicamente situado: Histórias de vida, valores humanistas e consciência crítica de professoras do centro tecnológico da UFSC. Tese de Doutorado em Educação Científica e Tecnológica não publicada, Universidade Federal de Santa Catarina, Florianópolis.

Carvalho, M. P. de. (1996). Trabalho docente e relações de gênero: Algumas indagações. Revista Brasileira de Educação, 2, 77-84.

Carvalho, M. P. de. (1998). Vozes masculinas numa profissão feminina: 0 que têm a dizer os professores. Latin American Studies Association. Chicago. Recuperado em 2 set. 2009, em http://lasa.international.pitt. edu/LASA98/PintodeCarvalho.pdf

Castro, M. de. (1992). O conceito de gênero e as análises sobre mulher e trabalho: Notas sobre impasses teóricos. Cadernos RCH/UFBA, 17, 80-105.

Chamon, M. (2006). Trajetória de feminização do magistério e a (con)formação das identidades profissionais. Anais do VI Seminário Redestrado. Rio de Janeiro. Recuperado em 16 out. 2009, em http://www. fae.ufmg.br/estrado/cd_viseminario/index.htm

Diogo, M. F., \& Coutinho, M. C. (2010). A inserção de mulheres no setor de vigilância privada: Análises preliminares de um estudo de caso com gestores de empresas catarinenses prestadoras de serviços. Anais do III Seminário Internacional Trabalho e Gênero. Recuperado em 2 nov. 2011, em http:// www.cienciassociais.ufg.br/strabalhoegenero/?id_ pagina $=1281526185 \&$ site_id $=244$

Diogo, M. F., \& Maheirie, K. (2008). Os sentidos atribuídos ao trabalho doméstico para serventes de limpeza. Cadernos de Psicologia Social e do Trabalho, 11(2), 257-272. Recuperado em 11 set. 2009, em http://www. revistasusp.sibi.usp.br/pdf/cpst/v11n2/a09v11n2.pdf

Fonseca, T. M. G. (2000). Gênero, subjetividade e trabalho. Petrópolis: Vozes.

Hirata, H. (2002). Nova divisão sexual do trabalho? Um olhar voltado para a empresa e a sociedade. São Paulo: Boitempo. 
Hirata, H., \& Kergoat, D. (2008). Divisão sexual do trabalho profissional e doméstico: Brasil, França, Japão. In A. de Oliveira et al. (Org.). Mercado de trabalho e gênero: Comparações internacionais (pp. 263278). Rio de Janeiro: FGV.

Kuenzer, A. Z. (2002). Conhecimento e competências no trabalho e na escola. Boletim Técnico do Senac. São Paulo. (Vol. 282, p. 45-68). Recuperado em 10 dez. 2007, em http://www.senac.br/BTS/282/boltec282a.htm.

Lombardi, M. R. (2006). Engenheiras brasileiras: Inserção e limites de gênero no campo profissional. Cadernos de Pesquisa, 36(127), 173-202. Recuperado em 11 fev. 2009, em http://www.scielo.br/scielo. php?pid=S0100-15742006000100008\&script=sci_ arttext\&t lng=es

Lopes, M. J. M., \& Leal, S. M. C. (2005). A feminização persistente na qualificação profissional da enfermagem brasileira. Cadernos Pagu, 24, 105-125. Recuperado em 21 out. 2009, em http://www.scielo.br/ pdf/\%0D/cpa/n24/n24a06.pdf

Martines, W. R. V., \& Machado, A. L. (2010). Produção de cuidado e subjetividade. Revista Brasileira de Enfermagem, 63(2), 328-333. Recuperado em 2 nov. 2011, em http://www.scielo.br/pdf/reben/ v63n2/25.pdf

Marx, K. (1998). 0 capital: Crítica da economia política (16a ed.). Rio de Janeiro: Civilização Brasileira. (Livro 1. Originalmente publicado em 1867).

Marx, K., \& Engels, F. (1981). A ideologia Alemã. Portugal: Presença; Brasil: M. Fontes. (Trabalho original publicado em 1845/1846).

Melo, H. P. de, Considera, C. M., \& Di Sabbato, A. (2007). Os afazeres domésticos contam. Revista Economia e Sociedade, 16(3), 435-454. Recuperado em 12 abr. 2009, em http://www.scielo.br/pdf/ecos/v16n3/06.pdf

Moreira, M. C. N. (1999). Imagens no espelho de Vênus: Mulher, enfermagem e modernidade. Revista Latino-americana de Enfermagem, 7(1), 55-65. Recuperado em 11 out. 2009, em http://www.scielo.br/ pdf/rlae/v7n1/13449.pdf

Nogueira, C. M. (2004). A feminização no mundo do trabalho: Entre a emancipação e a precarização. Campinas: Autores Associados.
Padilha, M I. C. de S., Vaghetti, H. H., \& Brodersen, G. (2006). Gênero e enfermagem: uma análise reflexiva. Revista de Enfermagem da UERJ, 14(2), 292-300. Recuperado em 11 out. 2009, em http://www.portalbvsenf.eerp.usp.br/scielo

Perosa, G. (2008). Educação diferenciada e trajetórias profissionais femininas. Revista Tempo Social, 20(1), 51-68. Recuperado em 11 out. 2009, em http://www.scielo.br/pdf/ts/v20n1/a03v20n1.pdf

Perreli, M. T. (2005). Mulheres do petróleo: Sentidos atribuídos por homens e mulheres a tarefas tradicionalmente consideradas masculinas. Dissertação de Mestrado em Psicologia não publicada, Universidade Federal de Santa Catarina, Florianópolis.

Rabelo, A. O. (2007). Gênero e profissão docente: Impactos na memória das normalistas. Revista Ártemis, 6, 58-67. Recuperado em 11 out. 2009, em http:// www.prodema.ufpb.br/revistaartemis

Rago, M. (1997). Trabalho feminino e sexualidade. In M. Del Priore (Org.). A história das mulheres no Brasil (pp. 578-606). São Paulo: Contexto.

Rago, M. (1998). Epistemologia feminista, gênero e história. In J. M. Pedro \& M. P. Grossi (Org.). Masculino, feminino, plural: Gênero na interdisciplinaridade (pp. 21-41). Florianópolis: Mulheres.

Saffioti, H. I. B. (1992). Rearticulando gênero e classe social. In A. de O. Costa \& C. Bruschini (Org.). Uma questão de gênero (pp. 183-215). Rio de Janeiro: Rosa dos Tempos; São Paulo: Fundação Carlos Chagas.

Santos, C. B. dos, \& Luchesi, L. B. (2002). A imagem da enfermagem frente aos estereótipos: Uma revisão bibliográfica. Anais do 8 Simpósio Brasileiro de Comunicação e Enfermagem. São Paulo. Recuperado em 11 set. 2009, em http://www.proceedings.scielo. br/scielo.php?script=sci_arttext\&pid=MSC0000000 052002000200009\&lng=en\&nrm=iso

Santos, E. A. dos (2008). Profissão docente: Uma questão de gênero? Anais do Seminário Internacional Fazendo Gênero 8. Florianópolis. Recuperado em 11 set. 2009, em http://www.fazendogenero8.ufsc.br/ sts/ST8/Elizabeth_Angela_dos_Santos_08.pdf

Scott, J. (1995). Gênero, uma categoria útil de análise histórica. Revista Educação \& Realidade, 16(2), 5-22. 
Silva, H. L. F. da (2006). Limites na construção de uma identidade política: Condicionantes de gênero e de classe sobre o trabalho docente na educação infantil. Revista Sociedade e Cultura, 9(2), 327-337. Recuperado em 11 nov. 2009, em http://www.revistas. ufg.br/index.php/fchf/index

Soares, A. (2010). As emoções do "care". Anais do Colóquio Internacional o que é o "care"? Emoções, divisão do trabalho, migrações. Universidade de São Paulo. Recuperado em 2 nov. 2011, em http://fflch. usp.br/ds/pos-graduacao/downloads/2010_care_ texto5.pdf

Soares, C., \& Oliveira, S. (2004). Gênero, estrutura ocupacional e diferenciais de rendimento. Revista Econômica, 6(1), 5-33. Recuperado em 11 out. 2009, em http:// www.uff.br/revistaeconomica/v6n1/cristiane.pdf

Sorj, B. (2010). Os cuidados com a família e as desigualdades de gênero e de classe. In A. Costa et al. (Org.). Divisão sexual do trabalho: Estado e crise do capitalismo (pp. 57-66). Recife: SOS Corpo; Instituto Feminista para a Democracia.

Souza, A. N. de (2008). Condições de trabalho na carreira docente: Comparação Brasil-França. In A. de Oliveira et al. (Org.). Mercado de trabalho e gênero: Comparações internacionais (pp. 355-370). Rio de Janeiro: FGV.

Souza, C. P. de, Catani, D. B., Souza, M. C. C. C. de, \& Bueno, B. O. (1996). Memória e autobiografia: Formação de mulheres e formação de professoras. Revista Brasileira de Educação, 2, 61-76. Recuperado em 16 out. 2008, em ttp://www.anped.org.br/rbe/rbe/rbe.htm
Stecher, A., Godoy, L., \& Díaz, X. (2005). Relaciones de producción y relaciones de género en un mundo en transformación. In L. Schvarstein \& L. Leopold (Org.). Trabajo y subjetividad: Entre lo existente y lo necesario (pp. 71-111). Buenos Aires: Paidós.

Unifem. Rumo à igualdade de gênero. Fundo de Desenvolvimento das Nações Unidas para a Mulher/UNIFEM. Brasília/DF. Recuperado em 13 mar. 2009, em http://www.unifem.org.br

Urbano, M. (2009). Mulher \& magistério, feminilização \& feminização. WebArtigos.com. Recuperado em 2 nov. 2011, em http://www.webartigos.com/ articles/25416/1/-MULHER-amp-MAGISTERIO-FEMINILIZACAO-amp-FEMINIZACAO/pagina1. html\#ixzz1DCxtEw3C

Wainberg, S. (2004). Experiências e vivências de auxiliares de enfermagem do sexo masculino no exercício de uma profissão majoritariamente feminina. Dissertação de Mestrado em Psicologia Social e Institucional não publicada, Universidade Federal do Rio Grande do Sul, Porto Alegre.

Yannoulas, S. C. (2002). Dossiê: Políticas públicas e relações de gênero no mercado de trabalho. Brasília: CFEMEA, FIG/CIDA. 